\title{
BLENDED LEARNING IN HIGH TECH MANUFACTURING: A CASE STUDY OF COST BENEFITS AND PRODUCTION EFFICIENCY
}

\author{
Veena Mahesh, Ph.D. and Craig Woll, Ph. D. \\ Intel Corporation
}

\begin{abstract}
The complexity of equipment and cost of training are increasing annually for high tech semiconductor manufacturing. The article describes the process and methodology adopted by a team at Intel Corporation to convert a 12-day class on equipment training into a blended solution consisting of a 5-day Classroom experience, a 3-hour Web Based Training (WBT), and a Managed Preventive Maintenance (MPM) for On-the-Job Training (OJT). The results of the implementation demonstrated a $60 \%$ reduction of technician time away from the factory, benefits cost ratio of 2.27 , and an ROI of $157 \%$. Based on the results of evaluation, the authors concluded that blended learning is a viable and cost effective solution to provide support for equipment training at Intel from the perspective of the lead time to proficiency, ROI, and cost benefit analyses.
\end{abstract}

\section{KEYWORDS}

Blended Learning, Equipment Training, Costs and Benefits, ROI, Proficiency, Kirkpatrick, Semiconductor

\section{INTRODUCTION}

Increasing competition in the global semiconductor manufacturing industry is leading companies to look for every possible way to increase tool utilization time, decrease operating expenses, and eliminate defects in production. Many of these problems can be solved through the improvement of human performance. This performance is often improved via learning interventions. These learning interventions can potentially cause two distinct problems. The first is an increase in the technician time away from the factory. The second is an increase in the production tool downtime for training activities. The use of blended learning techniques at Intel has led to the reduction in tech time away from factory and the reduction of production tool downtime for training by $60 \%$ or more.

Decreasing ramp and technology life cycles have made it imperative for Intel to ensure that technicians are not away from the factory for extended periods of time. The separation of the technician from the factory for the purpose of training leads to increases in costs for coverage and may increase the technician to tool ratios to compensate for the time away. Removing the learning event from the workplace also denatures the true environment of tool configuration and maintenance tasks that are being taught. This denaturing can create barriers to transfer of knowledge. When knowledge is not properly transferred the opportunity for error increases, leading to an increase in tool downtime for repair and an increase in defects along the production line.

Some learning events occur right on the factory floor utilizing the existing infrastructure as a means of reducing the cost of the training and decreasing the level of denaturing. This training requires the 
complete dedication of a tool for a predetermined time, decreasing the tool utilization rate. On constrained toolsets this translates into a reduction in total product throughput in the factory. In addition, performing intrusive tasks on the tools creates an opportunity to introduce defects into the system by performing unnecessary maintenance on a healthy tool.

These factors combined with the lack of availability of supplier instructors for overlapping class offerings at multiple sites have been constraints. The high cost of travel, technician time away from the factory, inadequate training materials and extensive training tool down-time have all been identified as gaps in meeting manufacturing technician training needs. Additionally, most equipment training is delivered in the instructor led model and does not leverage technology based learning or enable collaboration across geographies among peers.

\section{BACKGROUND AND OVERVIEW}

According to a survey of learning professionals across the U.S. and U.K. by Balance Learning, blended learning accounts for $16.1 \%$ of all training in the U.S. and $77 \%$ of all U.S. organizations currently use blended learning [1]. Blended learning is popular today, but the concept has been around for decades. To most of us, blended learning is a mixture of e-Learning with classroom training. Today's blended learning models are based on years of experience but apply new technologies and delivery options [2]. A blended learning solution typically includes any possible combination of a wide range of learning delivery media designed to solve specific business problems such as face to face classrooms, web based courseware, live virtual classrooms, onsite labs, job aids, Electronic Performance Support Systems, mentoring programs, communities of practice and portals. Driscoll [3] expands that concept to cover not just delivery methods (virtual classroom, self paced leaning), but also combinations of pedagogical approaches (for example, constructivism, behaviorism and cognitivism) and instructional technologies (web-based learning and synchronous distance learning) to produce optimal learning outcomes.

While training typically consists of traditional delivery methods (classrooms, labs, lectures, demonstration, self-study, seminars, conferences, job aids, presentations), blended learning involves interactive learning activities (discussion, simulation, role-playing, experimental, mentoring, interactivity, case studies, games, support). Blended learning goes beyond good and basic training to a more systematic education that promotes ongoing learning [4]. Driscoll [3] urges proponents of blended learning to combine instructional technology with actual job tasks in order to create a harmonious effect of learning and working. Blended learning paths help evolve organizations to the highest stage of executing their stated learning management strategies through the evolutionary stages of organizational learning [5].

The definition we have adopted at Intel is oriented with an integrated view of formal and informal learning. The approach we are adopting typically includes any possible combination of a wide range of learning delivery media designed to solve specific business problems such as classroom, web based courseware, live virtual classrooms, onsite labs, job aids, games, simulations, Electronic Performance Support Systems, mentoring programs, communities of practice, portals and communication. This approach has been used at Intel for several types of training including the e-Basics curriculum and a program to provide training to Intel's worldwide workforce and resellers [6, 7].

From a philosophical perspective of learning theories, the theory that best embodies the beliefs embedded in the Intel Blended Learning (IBL) program is the theory of connectivism [8] which states that "Learning is a process that occurs within nebulous environments of shifting core elements-not entirely under the control of the individual. Learning (defined as actionable knowledge) can reside outside of ourselves 
(within an organization or a database), is focused on connecting specialized information sets, and the connections that enable us to learn more are more important than our current state of knowing” [8]. Based on this theory, it is of utmost importance to connect specialized nodes or information sources while nurturing and maintaining connections to facilitate continual learning.

Learning is a process or "an ongoing experience involving the delivery of learning events across time and space" according to Bielawski and Metcalf [9]. The authors also point out that in most situations, it is difficult to distinguish where learning leaves off and where performance support begins and how knowledge management ties into these solutions. Thus, the goal of blended learning at Intel is combine all these approaches successfully so that formal learning activities are integrated with actual on-the-job activities to accomplish a specific learning goal. Another advantage of blended approaches is increased flexibility for learners enabling them to complete self-paced units at their convenience. Designers of the learning experience also find increased flexibility in implementing blended models because they are able to fit the skills being taught to the audience learning them.

Recent literature shows that blended learning is the most suitable for and the most popular among companies that are trying to reduce performer time away from jobs. The disadvantage of following an exclusively instructor-led approach is that it can cause employees to miss work and demand that they travel to classroom sessions. Blended learning models result in cost savings since employees spend less time in the classroom [7, 10] and also helps reduce time to certification. At Intel, the blended implementation of e-Basics curriculum resulted in cost savings of $\$ 12$ million in about 15 months primarily due to students spending less time away from the job and due to reduced resources allocated towards in-class sessions including instructor time, facilities, etc. [7] This paper describes another blended learning implementation at Intel that also resulted in significant cost savings.

Blended learning if designed well, takes advantage of the assets of both instructor-led training and elearning. It can be designed to enable greater interaction, social negotiation, and teamwork among students. Virtual classes, online learning environments, electronic conferences, instructor led classes and virtual dialogic learning communities where the "process of changing thoughts, ideas and information" is taking place [11, p.16] not only help students to explain their interpretations and listen to others' understandings, even when space and time separate them, they also enable students to communicate and receive feedback from the teacher [12]. According to Vygotsky [13], all learning is inherently social and learners benefit most from social interactions concerning tasks that they perform in collaboration with more knowledgeable or more experienced individuals.

A number of studies and reports indicate that a blend of learning methods or a hybrid model is better than any single modality of delivery on its own, regardless of content [1, 2]. The Thomson NETg Job Impact Study [14] also showed that blending of any type increases mastery on a task:

Regardless of the specific instructional components used, a well-defined blended learning solution designed around scenario-based exercises heightens overall on-the-job performance (speed and accuracy) over non-blended learning [14].

While the impact of blended models on learning mastery and accuracy are important, the real value of blended learning lies in its potential to create learning experiences that can provide the right learning at the right time and in the right place for each and every individual while helping learners connect across global boundaries, cultures and time zones [15]. 


\section{CASE SYNOPSIS}

Intel utilizes thousands of manufacturing technicians to operate and maintain its factories. To minimize product defects, each technician works in one of the cleanest environments in the world. Intel and other semiconductor manufacturers limit the particulates released in the factory environment by gowning each technician in clean room attire with goggles and other gear as necessary.

Many of the manufacturing technicians are responsible for operating, performing preventative maintenance, and troubleshooting equipment. The performance of these tasks requires Intel to focus on hiring technicians with some core technical competencies. These core competencies of the manufacturing technicians vary by site and by geographic location. There are some challenges associated with delivery of blended solutions across a large variety of geographic locations. Each location has a different mix of manufacturing technicians. At some sites there are many knowledgeable and experienced technicians available. In other geographic locations there are very few technicians with the base knowledge and experience to successfully participate in the course. In all cases the experienced technician's time is a precious commodity that cannot be wasted. Instructional designers at Intel have to consider the time, experience, and formal education of the technicians because they directly impact course content, design, and delivery.

Each factory is equipped differently and access to a personal computer for training on the factory floor is limited in some sites. This makes delivery of blended learning solutions a challenge. As more and more of these and other courses are delivered electronically within the factory a more robust delivery system will be necessary. For the present, Intel has the capability to deliver blended solutions across all geographic locations using a combination of self-paced web modules, instructor led training and skills practice modules.

The equipment that is identified for blended solutions often has a high percentage of utilization. Tool downtime for training is limited as the tool is needed for production. The scheduling of a course must coincide with known tool time availability for the sake of training.

\section{SOLUTION DESCRIPTION}

Students needed to acquire various components of knowledge and skill pertaining to specific equipment used for semiconductor manufacturing. Content was determined to consist of elements that fit into the cognitive and psychomotor domains. Upon taking into account training conditions, delivery environment and resource availability (people, infrastructure capabilities, dollars) and most importantly, target audience characteristics, we determined that the best solution would be a blended format using simulations, scenarios, and interactivities for higher retention rates. The key was to provide experiential learning so that our technicians could learn knowledge and skills through experience and hands-on approaches.

The blended learning approach we outlined is a performer-centric learning model that is focused on enabling technicians to accomplish learning goals within the context of the factory using a combination of solutions including experiential learning and self-paced learning, as well as collaborative and instructor led models. The program team implemented four different courses for Fabrication (Fab), Sort and Assembly-test audiences in the domain of factory equipment training. The team took the 12-day instructor led course in class and on the equipment and performed analysis on it. The course content is centered on the components, usage, and maintenance of equipment (or semiconductor manufacturing tool) known as 'testers' which are an integral part of the semiconductor manufacturing process. The content for the 
course is mostly provided by and owned by the supplier of the tool. Based on a detailed content analysis in partnership with the supplier, we were able to convert the 12-day class into a blended solution consisting of the elements shown in Figure 1.

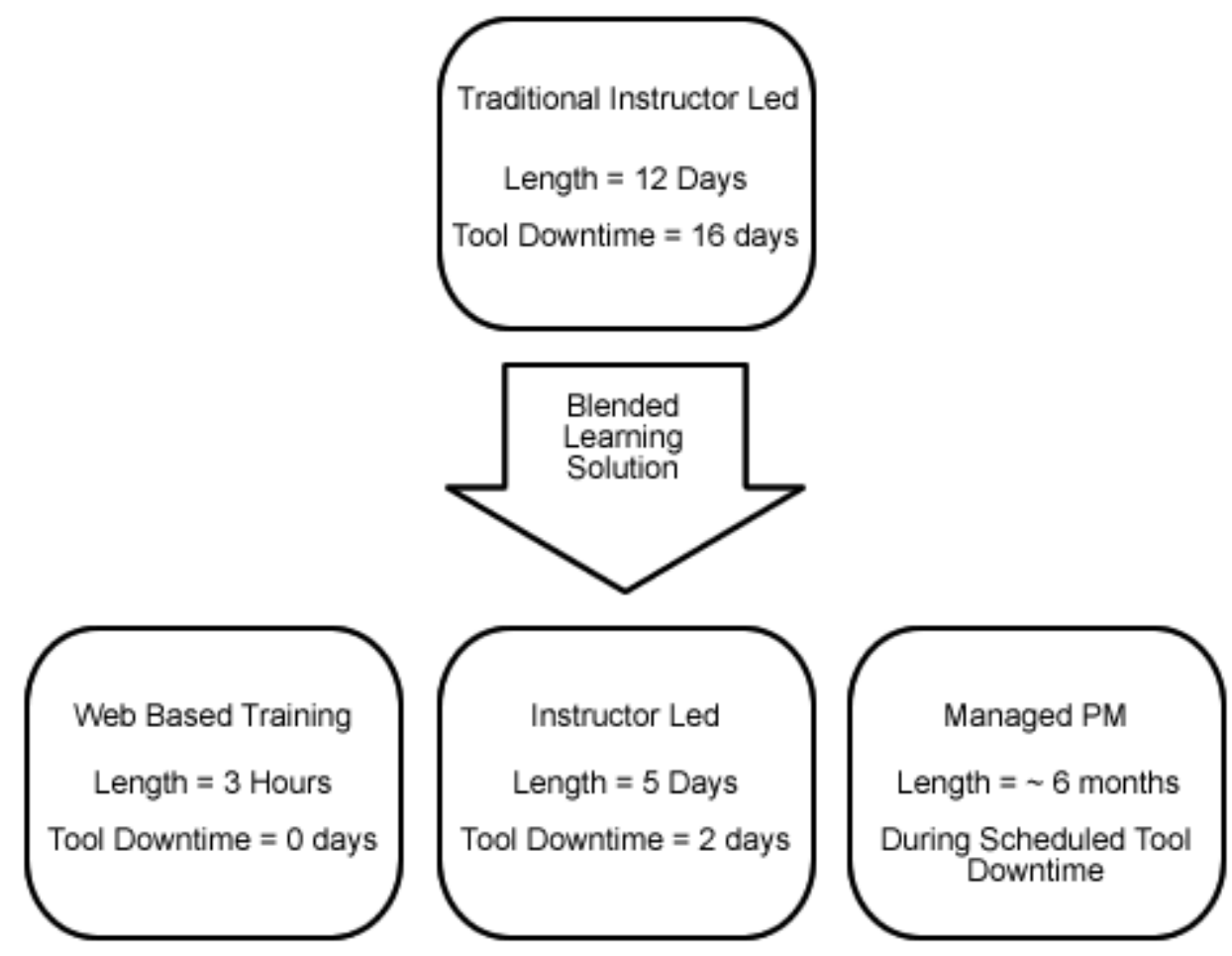

Figure 1. Graphical Representation of Traditional and Blended Solution Components

The blended course enables learners to obtain job-relevant basic cognitive objectives through the selfpaced web-based module. The solution blend was comprised of web-based and traditional classroom and web based delivery combined with a proven on-the-job Training (OJT) method entitled Managed Preventative Maintenance (MPM). Figure 2 outlines the delivery components and the skills and knowledge addressed by each intervention.

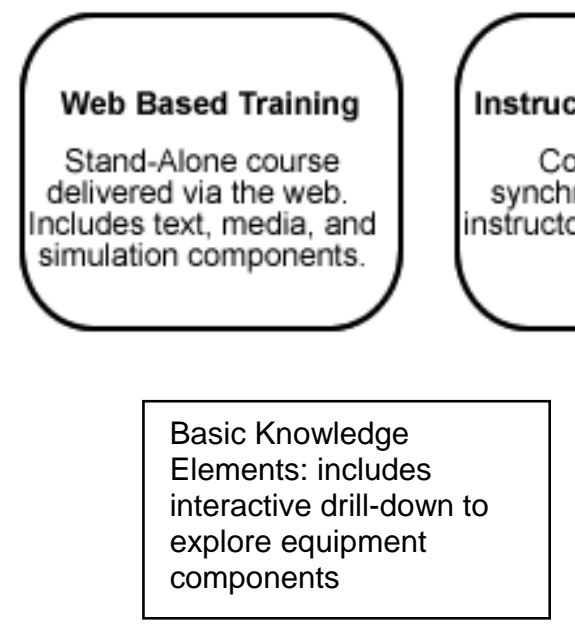

Advanced Knowledge Objectives: Includes videos of preventative maintenance tasks

\section{Managed PM}

Hands-on practice performed during schedule tool downtimes.

Figure 2. Delivery Components and the Skills and Knowledge Addressed By Each Intervention of the Blended Solution 
The initial 12-day course required 16 days of tool downtime. Ten days were used for training over a two week timeframe. The tools stayed down on the weekend for 2 days and then required 2 days to come back into production. In the blended learning approach we were able to put the more intrusive tasks into Managed Preventative Maintenance (MPM), preventing the need to bring the tool down more than 2 days. The MPM utilizes existing tool downtime intermittently over a six month period to train without a noticeable increase in tool downtime for instruction.

The blended solution required students to come in with pre-requisite knowledge of tester tools. The IBL team developed a Web Based Training (WBT) course that included an interactive Virtual Precision Measuring unit (VPMU) module that allows students to apply the knowledge about basic testers using a working simulator of the tester unit. This VPMU was built entirely on a flash platform. The solution goes beyond basic page-turning functionality by enabling learners to apply the knowledge they have learned in the WBT through a software simulation of a Virtual Precision Measurement Unit (VPMU). The simulation includes an interface of the digital test equipment that allows students to manipulate knobs and set values of various parameters and then enables them to simulate the test as it would run on the factory floor. The simulation provides students with real-time feedback on the test, informs them which components of the test failed, enables them to reset parameters, refers to the web-based course and then continuously applies their knowledge until they have learned the correct parameters and values needed to perform various tests. The WBT is now being used for training new personnel on the fundamentals of tester operation for the Fabrication, Sort and Assembly Test areas of the semiconductor manufacturing process. This course is also a prerequisite to the blended learning course described above.

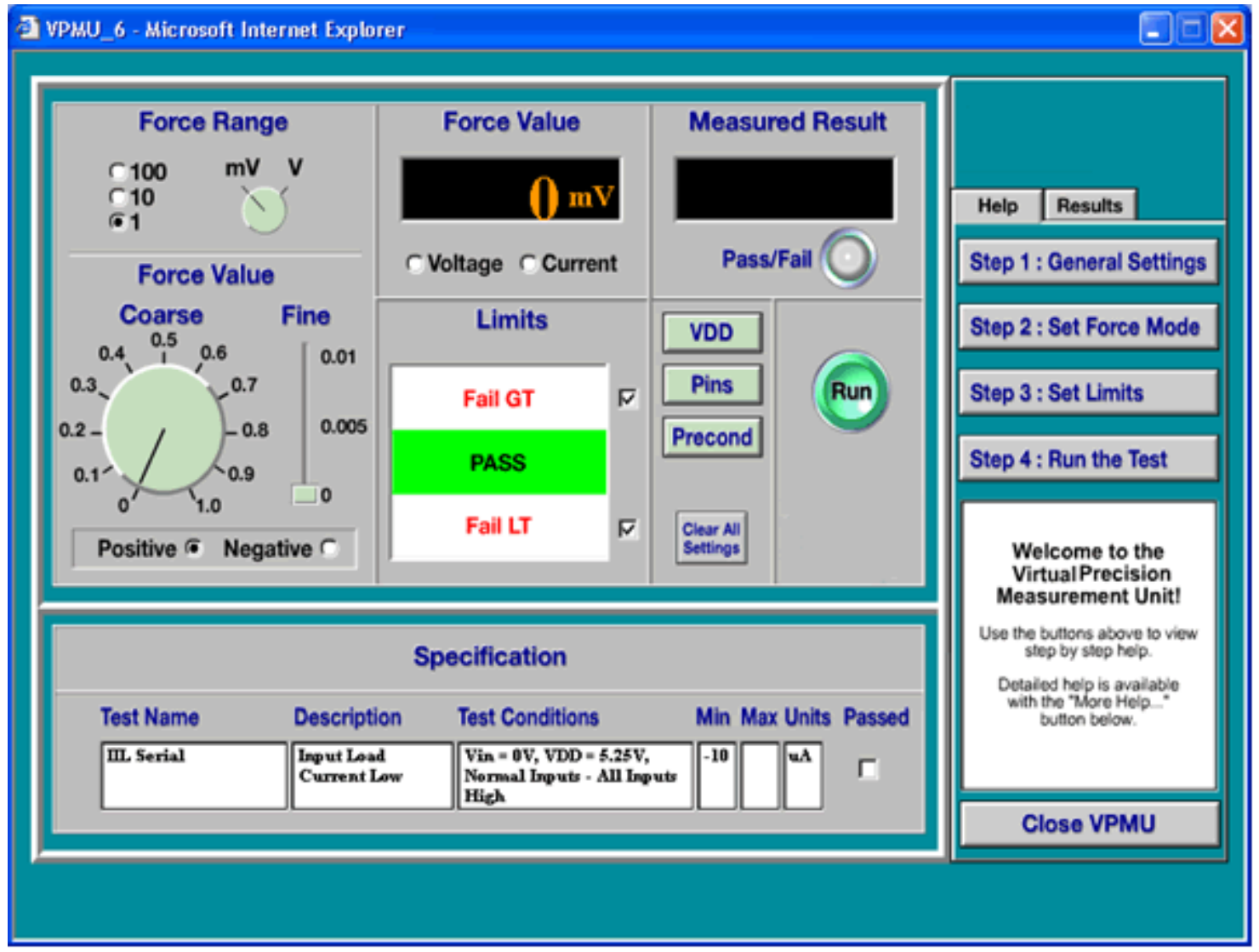

Figure 3. Screen Shot of the Interactive Virtual Precision Measuring Instrument Used in the Pre-requisite Course for the WBT 
The Web Based Training is the first component of the blended course. Students are expected to complete this self-paced module to gain the basic knowledge components about the various parts of the tester equipment. The WBT delivery consisted of mainly text and images and contained a knowledge check at the end of the course. Students are also allowed to test out of the WBT if they already had basic knowledge about the functioning of the tester unit; this allowed experienced technicians to complete this module without the drudgery of going through the WBT.

The next module in the blended solution is the instructor led class which covered the advanced knowledge and critical skills needed for operating the tester. This session allowed students to actively engage with the instructor and other students in a face-to-face setting and practice critical skills in a hands-on manner on real equipment available as part of the learning setting. This instructor led portion of the class was also followed by a knowledge check to ensure that learning goals were met.

The Managed PM component of the blended solution has a focus on a hands-on approach for critical equipment maintenance skills. The MPM approach is an in-house approach focused on measuring quality, independence and efficiency with which the technicians can increase their knowledge and productivity while on the job. MPM uses a structured delivery mechanism through hands-on practice for training on a specific piece of equipment and enables technicians to individually demonstrate critical skills needed to work on the equipment in a concentrated learning environment. MPM helps reduce production tool downtime for training by leveraging previously scheduled equipment down time for skills practice resulting in a flexible and cost-effective solution.

The blended approach, particularly MPM, enables us to proliferate key knowledge and skills and develop people with Deep Smarts [16]; people who do work with good quality and exercise good judgment in everything they do. This type of worker is essential to the working of a good company and they possess experience-based deep knowledge of a specific area of the company's business. Blended learning leads to the transfer of Deep Smarts (not just knowledge and skills). According to Leonard and Swap [16], the most efficient way to transfer Deep Smarts is through the use of knowledge coaches or experts who were motivated to share some of their deep smarts with protégés. Knowledge coaches provide guided experience to trainees enrolled in the MPM session which involves learning by doing, with immediate feedback loops. This approach creates deep understanding and allows the technician to gain knowledge they need as tied to specific contexts with tacit dimensions. The guided learning activities happen on the job, so the business situations are real and relevant to today's problems.

In speaking about blended learning, an important distinction has to be made between blended curricula and blended courses. Blended curricula involve different elements of the curriculum delivered using diverse delivery methods; this model has been around for decades. The blended course approach involves delivering a single course using hybrid delivery methods and therefore involves the need for tight instructional alignment and coordination. The program we are referring to in this article was responsible for implementing a blended course and not a blended curriculum.

\section{DEVELOPMENT APPROACH}

The blended learning courses developed by IBL leveraged existing content provided by suppliers of equipment to Intel for both courses by entering into a legal agreement with the suppliers. Additional content that was part of a course developed by Intel were also included where possible. The team also used an inhouse tool that converts content from template to a web based toolset to build the web based modules. Both these strategies allowed the team to develop and deliver the blended learning solution efficiently. 
New business processes associated with administering and delivering each component of the blended solution were introduced and added a layer of complexity to the course implementation. Without these new processes the delivery and tracking of the blended solutions would be impossible. Although these methods of deployment, especially for the MPM solution, were completely manual in the initial implementation of the course, future implementations will explore the possibility of increased automation in the delivery and tracking of course completions.

The entire IBL solution has been created and deployed using standard Intel systems. Table 1 outlines the various technical elements of the blended solution along with details on roles involved in development as well as the deployment strategy for the solution.

\begin{tabular}{|c|c|c|c|c|}
\hline $\begin{array}{l}\text { Blended Solution } \\
\text { Component }\end{array}$ & $\begin{array}{l}\text { Technology } \\
\text { Element }\end{array}$ & Purpose & Stakeholder Roles & $\begin{array}{l}\text { Deployment } \\
\text { Strategy }\end{array}$ \\
\hline \multirow[t]{3}{*}{$\begin{array}{l}\text { Web Based } \\
\text { Training (WBT) }\end{array}$} & $\begin{array}{l}\text { Content Capture } \\
\text { Template (MS } \\
\text { Word) }\end{array}$ & $\begin{array}{l}\text { Capture content within } \\
\text { predefined template } \\
\text { using word processor }\end{array}$ & $\begin{array}{l}\text { IBL team - design } \\
\text { and develop } \\
\text { SME - Review } \\
\text { design and } \\
\text { development }\end{array}$ & Not Applicable \\
\hline & $\begin{array}{l}\text { Graphics, } \\
\text { Interactive } \\
\text { Macromedia } \\
\text { Flash elements }\end{array}$ & $\begin{array}{l}\text { Create visual elements } \\
\text { for WBT module and } \\
\text { embed within Web } \\
\text { Authoring Toolset }\end{array}$ & Media Developer & Not Applicable \\
\hline & $\begin{array}{l}\text { Web Authoring } \\
\text { Toolset (Created } \\
\text { in-house) }\end{array}$ & $\begin{array}{l}\text { Intel web authoring tool } \\
\text { exports to HTML, } \\
\text { JavaScript, and Flash }\end{array}$ & $\begin{array}{l}\text { IBL team - design } \\
\text { and develop } \\
\text { SME - Review } \\
\text { design and } \\
\text { development }\end{array}$ & $\begin{array}{l}\text { Online Learning } \\
\text { Network (OLN) } \\
\text { framework; one of } \\
\text { Intel's internal } \\
\text { systems for } \\
\text { delivering WBTs via } \\
\text { intranet }\end{array}$ \\
\hline \multirow[t]{3}{*}{$\begin{array}{l}\text { Classroom } \\
\text { Experience }\end{array}$} & $\begin{array}{l}\text { Intel Standard } \\
\text { classroom } \\
\text { template }\end{array}$ & $\begin{array}{l}\text { Create instructional } \\
\text { material }\end{array}$ & $\begin{array}{l}\text { IBL team - design } \\
\text { and develop } \\
\text { SME - Review } \\
\text { design and } \\
\text { development }\end{array}$ & $\begin{array}{l}\text { Intel University } \\
\text { standard classroom } \\
\text { delivery (scheduled } \\
\text { classroom training) }\end{array}$ \\
\hline & $\begin{array}{l}\text { Intel Standard } \\
\text { classroom } \\
\text { template }\end{array}$ & $\begin{array}{l}\text { Maintain and update the } \\
\text { product as needed }\end{array}$ & $\begin{array}{l}\text { Central corporate } \\
\text { training group } \\
\text { equipment training } \\
\text { product owners }\end{array}$ & $\begin{array}{l}\text { Intel University } \\
\text { standard classroom } \\
\text { delivery (scheduled } \\
\text { classroom training) }\end{array}$ \\
\hline & $\begin{array}{l}\text { Internal } \\
\text { registration } \\
\text { process }\end{array}$ & $\begin{array}{l}\text { Work through the Intel } \\
\text { University course } \\
\text { restricted registration } \\
\text { process }\end{array}$ & $\begin{array}{l}\text { Site training } \\
\text { coordinators and } \\
\text { technical training } \\
\text { officers }\end{array}$ & Not Applicable \\
\hline Managed PM & $\begin{array}{l}\text { MS Word } \\
\text { template }\end{array}$ & $\begin{array}{l}\text { Create instructional } \\
\text { material }\end{array}$ & $\begin{array}{l}\text { IBL team - design } \\
\text { and develop } \\
\text { document } \\
\text { SME - Review } \\
\text { tasks for accuracy }\end{array}$ & $\begin{array}{l}\text { One on one } \\
\text { coaching with } \\
\text { expert technician }\end{array}$ \\
\hline
\end{tabular}

Table 1. Summary of Technical Elements of Blended Solution, Roles Involved in Development and Deployment Strategy

The development of the blended course required overall coordination and collaboration across the various teams that were involved. Aside from basic project management, the development effort required close monitoring from an instructional design perspective to ensure complete alignment across the various components of the blended solution. 


\section{MEASUREMENT OVERVIEW}

The participants of this course included students from a wide variety of backgrounds and cultures. The target audience for the blended learning solutions has been equipment technicians in our factories in the Fabrication, Sort and Assembly/Test worlds. While the initial projects and the implementation have been focused on this audience, the approach and methodology are flexible enough to be applied toward any audience. The approach for the team has been focused on the need for the solution to be relevant to manufacturing technicians on the factory floor. The entire solution has been tailored to suit the equipment technician audience.

The Assembly/Test and Sort audiences have unique needs as far as learning style and language. Assembly technicians are culturally more inclined to learning within groups whereas Fab audiences are more suited to the individual self-paced learning style. The blended learning approach is flexible enough to be applicable to either of these audiences. The analysis phase of the approach ensures that solution selection is tailored to suit audience characteristics.

\section{A. Kirkpatrick/Phillips Evaluation Model}

The blended learning solution utilized a variety of evaluation levels to ensure that the solution was usable and relevant to the target audience. A summary of the levels of evaluation for each component of the blended solution is outlined in Table 2 .

Kirkpatrick Level 1 evaluations give information about the satisfaction of trainees with the training they receive, whereas, Level 2 evaluations provide information as to whether the students learned the course content outlined in the objectives of the course sufficiently to close the knowledge gap that was addressed [17].

\begin{tabular}{|l|c|c|c|c|}
\hline \multicolumn{1}{|c|}{ Component } & $\begin{array}{c}\text { Kirkpatrick } \\
\text { Level }\end{array}$ & Pre-test & Post-test & $\begin{array}{c}\text { Performance } \\
\text { Assessment }\end{array}$ \\
\hline Web-Based Training & 1 & & & \\
\hline Classroom & 2 & $\mathrm{X}$ & $\mathrm{X}$ & \\
\hline & 1 & & & \\
\hline Managed Preventative Maintenance & 2 & $\mathrm{X}$ & $\mathrm{X}$ & \\
\hline Overall Blended Solution & 3 & & & $\mathrm{X}$ \\
\hline
\end{tabular}

Table 2. Summary of Kirkpatrick’s Levels of Evaluation for Each Component of the Blended Solution

The Level 3 evaluation attempts to answer the question "Are the newly acquired skills, knowledge, or attitude being used in the everyday environment of the learner?" It most often represents the truest assessment of a program's effectiveness. Measuring at this level is difficult, and thus requires important decisions in terms of when to evaluate, how often to evaluate, and how to evaluate. Although it takes a greater effort to collect Level 3 data than it does to collect data during training, its value is important to the training department and organization. Behavior data at this level usually provides insight into the transfer of learning from the classroom to the work environment and the barriers encountered when attempting to implement the new techniques learned in the program.

Interviews were scheduled and conducted when an individual finished the Managed PM portion of the course. The individuals were first requested to complete an online survey of questions and then participate 
in the interview. For the interviews, the interviewers arranged to meet the participants either in a virtual or a face-to-face setting. In case of a virtual setting, the interviewer attempted to conduct the interview using a shared virtual environment so that participants could review the transcriptions of the interviewer and approve the capture of data. This data was then used for further qualitative analysis.

Evaluation of results at level 4 typically involves monitoring organizational improvement through work output and quality improvement, whereas at level 5, it is focused on cost savings and comparison of monetary benefits against costs. Jack Philips played a key role in extending Kirkpatrick's four levels of evaluation and defining the ROI model in detail [18]. The IBL program collected data and performed a detailed level $4 / 5$ analysis to obtain a cost/benefit ratio. The cost/benefit ratio is calculated by dividing the sum of the savings by the sum of the costs. The sum of the savings is calculated by comparing the difference in costs in the traditional method versus the blended learning method. The sum of the costs includes developer, project manager, and subject matter expert, and resources costs.

\section{B. IBL Methodology}

The Intel Blended Learning Program team has developed a methodology (see Figure 4) that includes process steps, quality criteria, design guidelines, templates and training models for use in future blended learning implementations. We plan on enabling suppliers with these guidelines and tools to develop and deliver training to Intel manufacturing technicians and supplier technicians. This methodology will also be available to Intel training groups who need to develop blended training solutions. The methodology that includes design guidelines and training models for use in future blended learning implementations is being developed and will be updated as a "living" process by the Intel Blended Learning Program team.

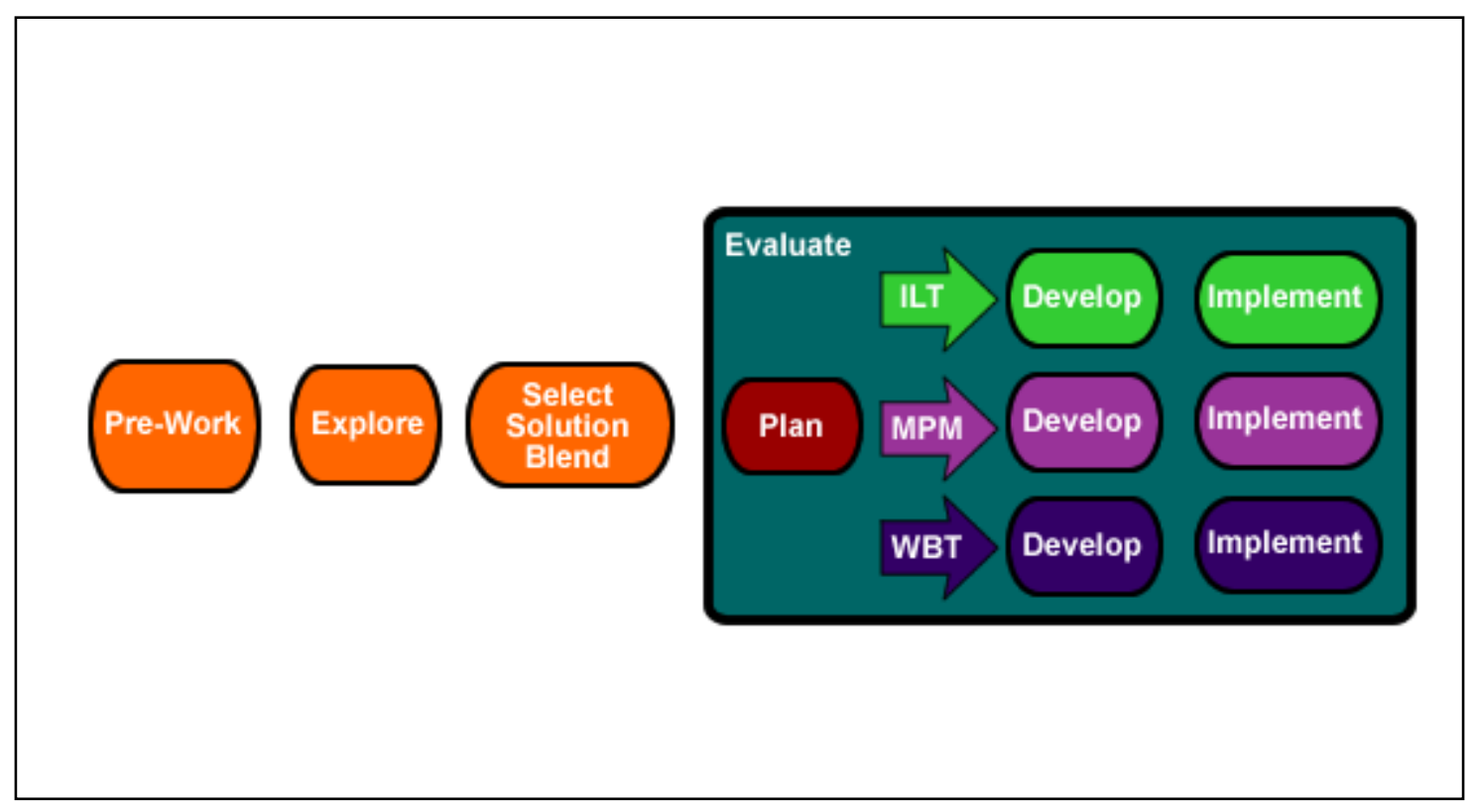

Figure 4: Intel Blended Learning Development Methodology

The vision is to enable this methodology to become a standard in the semiconductor industry thereby enabling our suppliers to deliver standard training using a blended approach for all toolsets. The methodology is being designed in a flexible manner so as to enable the inclusion of new components to the delivery model or the adaptation of the blended approach to include both formal and informal learning strategies. 


\section{MEASUREMENT RESULTS}

Data analysis consisted of a variety of different approaches for each part of the blended solution. The overall data consisted of both quantitative and qualitative data.

\begin{tabular}{|c|c|c|}
\hline Component & Kirkpatrick Level & Results \\
\hline \multirow[t]{2}{*}{$\begin{array}{l}\text { Web Based } \\
\text { Training } \\
\text { (WBT) }\end{array}$} & Level 1 & $\begin{array}{l}\text { WBT was at least as effective as a traditional approach (70\%) } \\
\text { Questions relative to the course design and content all received } \\
\text { very positive feedback ( } 80 \% \text { and above) } \\
\text { Level of difficulty of the course was just right }(83 \%)\end{array}$ \\
\hline & Level 2 & 93\% average score on Post-Test \\
\hline \multirow[t]{2}{*}{ Classroom } & Level 1 & $\begin{array}{l}\text { Training was equal to and potentially better than the traditionally } \\
\text { delivered training } \\
\text { Need for more time working hands-on with the tool during the } \\
\text { instructor led component. }\end{array}$ \\
\hline & Level 2 & $\begin{array}{l}81 \% \text { average score across sites; improvement of }+31 \% \text { at one } \\
\text { site and }+55 \% \text { at another }\end{array}$ \\
\hline Managed PM & $\begin{array}{l}\text { Level } 3 \\
\text { Survey/Interview }\end{array}$ & $\begin{array}{l}\text { Qualitative analysis showed an overall positive response to the } \\
\text { blended solution over the traditional delivery method }\end{array}$ \\
\hline $\begin{array}{l}\text { Overall } \\
\text { Solution }\end{array}$ & Level 4 & $\begin{array}{l}60 \% \text { reduction in equipment downtime for training. } \\
157 \% \text { ROI } \\
\text { Benefits Cost Ratio of } 2.27\end{array}$ \\
\hline
\end{tabular}

Table 3. Summary of Measurement Results for Components of Blended Solution

\section{A. Web Based Training}

The web based training component of the blended solution included an end of course survey to measure student reaction to the course. The responses were tabulated in Table 3 and the results show that despite the use of new technologies and instructional methods across global sites, the students felt comfortable utilizing the web based training element of the blended solution. In addition, each web based training course contained a pre- and post-test to measure the acquisition of knowledge as a result of the intervention administered. The web based training pre- and post-test were generated from a pool of questions related to the overall course objectives and content delivered. The passing requirement for the web based component was set at $70 \%$.

\section{B. Classroom}

The instructor led training aspect of the blended solution was reduced from the traditional format by $60 \%$. There was considerable interest in the impact of the reduction on learner satisfaction with the course. The data gathered in the end of course survey and the pre- and post-test are also summarized in Table 3.

\section{Managed PM Solution}

The Managed PM solution involved a completely unique deployment approach that involved students over an extended period of time; in order to obtain a detailed understanding of student experiences and seek to obtain an understanding of how students applied the knowledge they had gained, it became apparent that we would need to employ a qualitative approach for data gathering and analysis. We used a qualitative approach which seeks to understand how actions and roles influence participation and engagement within the hands-on OJT framework. Data analysis involved the collection of three different types of qualitative data: field notes, interview transcripts and other incidental data. 
Data analysis involved the use of a qualitative analysis software program called QSR nVivo to develop categories and code the data. Interviews with students were transcribed and coded for analysis. Once coding was done, searches were performed using a variety of operators.

The qualitative analysis showed the following positive and negative results:

\section{Positive}

Good opportunity to do more applied troubleshooting

Flexibility to implement the learning after the training

Course generally meets expectations

Participants said they were more able to perform troubleshooting and solve problems on their own after taking this course

Participants were able to achieve the stated objectives

Helped in the development of skill levels

Having an internal instructor helped facilitate good communication during learning

Facilitated gaining certification and confidence

Good to know where to go for a support line during the training

\section{Negative}

There was overlap between the MPM tasks and the maintenance tasks

Needs more immediate assessment of knowledge and skills before moving into the practice environment

Some confusion between the two different toolsets

Lack of hands-on

\section{Level 4/5 Evaluation Blended Learning Solution}

The business impact and return on investment (ROI) for the blended solution were calculated by dividing the total savings per year from tuition costs, technician time away from factory, and instructor costs by the development costs, including developers, project managers and subject matter experts. The results showed that there was a $60 \%$ reduction in equipment downtime for training. There was a $157 \%$ ROI and a Benefits Cost Ratio of 2.27. In addition there was no apparent difference in student reaction between the blended learning methods compared to supplier delivered, instructor led training.

\section{FINDINGS AND IMPLICATIONS}

\section{A. Effectiveness and Benefits}

An advantage of the blended learning approach is that learning is spread out over a longer period of time which better prepares the student for hands-on application and working on the tool. Time spent learning on the machine is more effective because learners already have a mental model (tool concepts, machine operation, task practice, and vocabulary) to build on. Students also stated that they had increased confidence during tool hands-on sessions and that they felt better prepared as a result of the blended approach.

Manufacturing process and the standardization of that process across various Intel sites is encapsulated 
within a key philosophy titled "Copy Exactly." Intel can credit "Copy Exactly" with enabling the company to bring factories online quickly with high-volume practices already in place, hence, decreasing time to market and increasing yields. "Copy Exactly" solves the problem of getting production facilities up to speed quickly by duplicating everything from the development plant to the volume-manufacturing plant. In particular, it means ensuring that the process devised at the development facility is fine tuned not just for performance and reliability, but for high-volume production as well. Today, the following parameters are copied exactly from the development plant to the high volume manufacturing plant: the process flow, equipment set, suppliers, plumbing, manufacturing clean room, and training methodologies.

One of the key benefits noted through the implementation of the blended course described above is that the design of the course is suitable for labor models across a wide variety of Intel sites and geographies resulting in maintaining the "Copy Exactly" philosophy. The implementation of the course also resulted in increased partnership among the dispersed factories in areas of share training tool sets and instructor resources.

Web-based training is no different from other means of training when it comes to the need for continued feedback and guidance through environmental cues, job aids, performance support, mentors, and experts; but web-based training has the advantage in that it's easier to post a question to an expert by email and get an answer than to find an expert in person; thus, learning is more flexible. Also, learners are a valuable source of the information needed to refine and improve an educational environment. Questions and comments that come to the learner while on the job can be fed back into the instructional development process in a structured manner. This creates a loop that can fuel the continuous development and improvement process. Providing incentives isn't difficult. People who contribute chunks of information deemed valuable to peers will receive recognition doing so. Learners who take on a valued teaching role become more committed learners.

Web-based learning modules enable learners to practice vocabulary and key tasks through simulations without instructor or machine. Rich media helps break down the language barrier common to the Assembly/Test audience. Real-time access to the technician/expert/instructor in different geographical locations has been proven as a fringe benefit. Each blended learning, instructor-led training intervention takes into account the two-way and interactive communication via conversation with the students instead of only a one-way lecture. The instructor/expert is a facilitator instead of a lecturer. During the Managed PM process the equipment expert/student real-time interaction accomplishes coaching and practice. The overall result is faster delivery of time sensitive training, updating the workforce quickly and frequently.

Everybody is familiar with the structures, techniques, and methods of traditional instructor-led, classroom training, and Web based training. Full use of the combination of learning styles and meeting business needs of the organization at the point of use demands different structures, techniques, and methods; however, blended learning isn't merely a delivery mechanism - it has the power to transform the learning experience. Instead of discrete courses that students used to attend at an equipment supplier site, they can now access a continuum of courses, group learning environments, simple job aids, performance support and learning on-demand using the blended approach.

Standard instructional design principles were applied in the development of these learning solutions. The web-based learning and virtual simulation modules were available for students to practice with as many times as they need, providing a flexible and efficient way of learning. 


\section{Reducing Technician Time Away From Factory (TTAF) and Tool Down Time}

There were two impacts that the IBL solution addressed: a lack of certified technicians to perform equipment maintenance, and the cost of corresponding equipment downtime. The program was able to show 30\% reduction in travel costs. When implemented in partnership with factory resources and equipment suppliers, blended learning has helped mitigate the costs associated with technician time away from the factory and tool downtime for training while enabling the reduction of Technician Time Away from Factory (TTAF) by over 50\%. The Managed PM solution resulted in a 30\% increase in availability of production tools through reduction of tool usage for training. This enabled increased availability of technician time for problem solving. Creation of the IBL solution resulted in resolution to both the impacts identified above while ensuring a quality solution resulting in significant cost-savings for Intel.

The blended learning solution was able to reduce the time required to bring a manufacturing tool down for a predetermined amount of time for training through implementation of the MPM solution. The result was an additional 11 days of tool up-time each time the course was implemented. Additional up-time translates into increased total product throughput. This was particularly significant because the tester tool that was considered for the program was a constraint tool for the Sort manufacturing process.

\section{Demonstrated Return On Investment (ROI)}

A detailed ROI analysis on the program revealed an ROI roughly a $157 \%$ return with an excellent benefits-cost ratio of 2.27. The training developed by the IBL team also resulted in a $50 \%$ reduction of training throughput time. Bersin [2] cautions us to think of blended learning as a tool to improve performance, and not as a tool to reduce costs. This perspective was more than validated by our blended learning implementation. Even though we did see significant reductions in cost, the improvement in performance are far more significant overall.

\section{B. Challenges and Risks in Implementing Blended Learning at Intel}

Some of the challenges and risks in implementing a global blended learning initiative in a large multinational corporation include disparate business processes, cultural differences, language barriers, and the ability to gather reliable evaluation data. Customizing the implementation to overcome these factors was one of the main challenges we faced. Separate business process flows were defined for each site that had varying business processes and systems, while translation and other localization techniques were utilized to overcome language-based issues. Localization was employed mainly for WBT content and level 3 evaluation. Despite the employment of localization, we learned that cultural learning styles may interfere with designed learning strategies. For example, we had designed the WBT module for completing key knowledge components to be implemented using a self-paced approach; however, we learned that in Asia, the delivery method included an instructor presenting the WBT content in a classroom format with translations incorporated to help alleviate issues with comprehension of English as a second language.

To overcome some of the barriers associated with a global implementation of blended learning interventions, we had to put several changed management practices in place. We found that the course administration systems and business processes available within Intel had not been designed to effectively support a blended learning solution. As a result, we had to introduce separate course codes for each IBL module to enable tracking at the individual element of the blend. Further, logistical overhead included non-standard business processes across global sites specifically for technical solutions pertaining to certification and tracking. These technical infrastructure gaps discovered during pilots will be plugged with the implementation of an enterprise-wide learning management system. Implementation of the Managed PM solution in particular required obtaining buy-off from a variety of key stakeholder groups 
Blended Learning and Localness: The Means and the End

and the articulation of some key changes to responsibilities for key roles such as site training coordinators.

Evaluation of the blended solution also presented a new set of complexities during the implementation of the blended solution. The evaluation method was complicated by the fact that data had to be gathered from multiple interventions in a variety of different formats (due to the fact that systems used for delivery of the solution elements were different). Business process for collecting evaluation data is different for each intervention.

\section{CONCLUSIONS AND RECOMMENDATIONS}

Overall, the impact data indicated that blended learning is a viable and cost effective solution to provide support for equipment training at Intel from the perspective of the ROI and cost benefit analyses. While it was no surprise that the effectiveness results for the WBT element of the blended solution were aligned with the scores for other traditional stand-alone WBTs, the major findings were centered on the student reaction data. Even though students had to go through a complex set of interventions in the blended solution, it was surprising to note that there were no apparent differences in student reaction between the blended learning method compared to the traditional monolithic training module. Blended learning in this case showed significant results in acceptance, comprehension, and return on investment. It is likely that results from future blended learning solutions will deviate some from current results based on situational factors, although it is not expected that these deviations will be significantly greater or less than the current results. Further analysis of blended learning solutions will be necessary to determine the variation across projects. The preliminary data on other courses to date at Intel show very similar results.

Clearly, a hands-on approach to learning was a huge favorite among technicians. The Managed PM module provides a structured framework for OJT without tool constraints and was an effective method of promoting experiential learning (learning by doing). In fact, our findings from the Level 3 analysis of the MPM module indicate that this learning by doing method is one of the key factors for retention of learning. MPM is a key element for BL, but we learned that implementing MPM without a good technical infrastructure can be inefficient as well as labor and time intensive.

An excellent technology infrastructure alone cannot make a blended learning solution effective, but ensuring that technology such as a Learning Management System (LMS) is available to track the completion of each and every component of the blended solution is very important. An LMS will also be useful in tracking whether pre-requisites are met prior to enrolment in the program. It is very important to realize that very few LMS systems have the ability to track all elements of a blended solution. For example, in our pilot implementation, we were able to track the completion of the web based and instructor led components of the program within standard learning systems within our company; however, the Managed PM program was entirely rolled out using a manual system for tracking student progress and only the final completion was tracked through a manual entry into our overall certification system. This implementation model was extremely labor intensive and required a lot of detailed planning and process support through a variety of different roles from partner organizations. Each site that implemented the program provided local implementation owners to ensure the smooth conduct of program, ownership of tracking and reporting of student progress and coordination of student training with preventative maintenance schedules within the factory for the MPM component. While we were able to implement the program in this manner, we are now considering developing an automated system to help ease the support needed for this element of the program. 
Designing blended learning for global audiences requires that designers examine the solution from all aspects, specifically the environmental, cultural and audience characteristics aspects and not just the pedagogical. Although our program was designed for the Sort manufacturing sites which are primarily located within the United States, our program was implemented globally within our Assembly-Test sites as well, due to the fact that they were also using the same tester tool and had a need for the program. As a result of this change, we encountered some site specific issues during our program implementation. Several of the learners at our Asian sites, particularly in China, were not very familiar with English and consequently this resulted in difficulties with deploying this complex program at those sites. We recommend exploring options for localization of learning content for international sites. This will need to be a separate effort funded appropriately to avoid site level implementation issues.

Implementing a successful blended learning solution requires that designers pay attention to simple logistical challenges that students might face. For example, we had designed our program so that each component of the blended solution was delivered at a different physical location. The student could complete the e-learning solution at a standalone computer or on their laptop. One key lesson we learned was that infrastructure capabilities at various sites was somewhat varied particularly in the area of speed of network access for web based components. In the future, we plan on enabling learning labs to make it easy for learners to attend and complete the technology based elements of the solution without having to worry about technical specification and configuration. It is also critical to design the program in such a way that sequencing of instructional modules, if any, is implemented correctly. This requires excellent documentation, communication and management to ensure that students complete the components of the blended solution in the specified order, so as to obtain the benefits of the intended design of the learning solution.

Another key to the success of the program was the work that went into the plan, launch, marketing and evaluation of the program. Support from management and site coordinators to facilitate and drive the program was critical for adoption of this new approach.

In our experience, the success of the blended course depended on the overall emphasis of standard instructional approaches, which were based on problem identification for defining the approach to blending, instructional development and evaluation techniques. Several team members had a strong background in instructional design and we also had successful partnerships with content experts, which contributed to the successful implementation of our program.

\section{SUMMARY}

The complexity of equipment and cost of training are both increasing annually for high tech semiconductor manufacturing. In addition, there is a demand that the lead times to proficiency decrease to support rapid product introductions as global competition increases. To meet the new demands requires an evolution from traditional learning to blended learning. Blended learning involves interactive learning activities (discussion, simulation, role-playing, experimental, mentoring, interactivity, case studies, games, support). Blended learning goes beyond good and basic training to a more systematic education that promotes ongoing learning [4].

Intel Corporation also feels the pressure to decrease costs while improving the quality of the learning experience in terms of lead time and proficiency. Based on a detailed content analysis in partnership with the supplier, we were able to convert the 12 day class into a blended solution consisting of a 5 day Classroom, a 3 hour Web Based Training (WBT), and a Managed Preventive Maintenance (MPM) for 
On-the-Job Training (OJT). The results of the blended learning implementation demonstrated a $60 \%$ reduction of technician time away from the factory, benefits cost ratio of 2.27, and an ROI of $157 \%$. Based on the results, blended learning is a viable and cost effective solution to provide support for equipment training at Intel from the perspective of the lead time to proficiency, ROI, and cost benefit analyses.

\section{ACKNOWLEDGEMENTS}

Thanks to Tomas Hall and Linda Humphrey for supporting the program and providing us with key elements for this article and to Randy Jensen for the evaluation and data analysis. Thanks to Terry Misley, Mike Lombardi and all other contributors of the Intel Blended Learning Program for making it a success.

\section{ABOUT THE AUTHORS}

Veena Mahesh is a Senior Knowledge Strategist in the Knowledge Enablement program for the Technology Manufacturing Group (TMG), of Intel Corporation. She received her $\mathrm{PhD}$ in Educational Technology from Arizona State University. Her work supports strategic efforts to improve utilization and transfer of knowledge, the development of effective methods and technology to enable key business processes and the improvement of knowledge management and learning practices across TMG.

Craig Woll is a Senior Learning Technologist for Intel Corporation. He received his $\mathrm{PhD}$ in Instructional Technology from Utah State University. He works with internal and external customers to develop strategic learning packages to meet Intel’s strategic objectives.

\section{REFERENCES}

1. Sparrow, S. Blended is Better. ASTD T+D Magazine 58(11): 55, November 2004.

2. Bersin, J. Blended Learning Handbook. San Francisco: Jossey-Bass, 2004.

3. Driscoll, M. Blended Learning: Let's Get Beyond the Hype. Retrieved in 2003 from http://www8.ibm.com/services/pdf/blended learning.pdf.

4. Billington, M. Training/Learning: What Fits Your Company? 2003. http://www.clomedia.com /content/templates/clo_feature_environment.asp?articleid=101\&zoneid=60.

5. THINQ Learning Management Maturity Model (LM3'TM), 2004.

6. Mantyla, K. Blending E-Learning: The Power is in the Mix. Alexandria, VA: ASTD Publications, 2001.

7. IDC Corporation. Customer Needs and Strategies: Semiconductor Manufacturer Company Reduces Costs and Triples Capacity with Global Blended Learning Program. Report: \# 3678, 2003.

8. Siemens, G. Connectivism: A Learning Theory for the Digital Age. International Journal of Instructional Technology \& Distance Learning, 2(1): 2005. http://www.itdl.org/Journal/Jan_05 /article01.htm.

9. Bielawski, L. and D. Metcalf. Blended eLearning: Integrating Knowledge, Performance Support, and Online Learning. Amherst, MA: HRD Press, 2003.

10. Brennan, M. Blended Learning: The Benefits of Combining eLearning and Classroom Instruction. Adapted from Blended Learning and Business Change: Study Excerpts and Key Findings. IDC Corporation, Report \# 29647, October 2003.

11. Lewis, J., J. Whitaker and J. Julian. Distance education for the 21st century: The future of national and international telecomputing networks in distance education. In: Z. L. Berge and M. Collins (Eds.), Computer-mediated Communication and the Online Classroom: Vol. 3. Distance Learning, 13-30. Cresskill, NJ: Hampton Press, 1995. 
12. Harasim, L. Online Education: Perspectives on a New Environment. New York: Praeger, 1990.

13. Vygotsky, L. S. Mind in Society: The Development of Higher Psychological Processes. Cambridge, MA: Harvard University Press, 1978.

14. Thompson NETg Job Impact Study, 2003. http://www.netg.com/Upload/us ThomsonJobImpactStudy.pdf.

15. Thorne, K. Blended Learning: How to Integrate Online and Traditional Learning. Sterling, VA: Kogan Page Limited, 2003.

16. Leonard, D. and W. Swap. Deep Smarts. Harvard Business Review 82(9): 88-98, September 2004.

17. Barksdale, S. and T. Lund. Rapid Evaluation. Alexandria, VA: ASTD, 2001.

18. Phillips, J. Handbook of Training Evaluation and Measurement Methods. Houston, TX: Gulf Publishing Company, 1997. 